\title{
Arte da pintura do ventre materno e vinculação pré-natal
}

\section{Art of maternal womb painting and antenatal attachment}

\author{
El arte de la pintura del vientre materno y el vínculo prenatal
}

\author{
Júnia Aparecida Laia da Mata ${ }^{1}$, Antonieta Keiko Kakuda Shimo ${ }^{2} \mathbb{D}$
}

Histórico
Recibido:
25 de enero de 2018
Aceptado:
10 de abril de 2018
1 Enfermeira Obstetra, Doutora.
Professora do Departamento de
Enfermagem Materno-Infantil
da Escola de Enfermagem
da Universidade Federal do
Rio Grande do Sul, Porto
Alegre- RS, Brasil. Autora
Correspondente. E-mail:
jumata.2905@gmail.com
2 Enfermeira Obstetra, Doutora.
Professora da Faculdade de
Enfermagem da Universidade
Estadual de Campinas,
Campinas-SP, Brasil.
Introdução: A Arte da Pintura do Ventre Materno é uma técnica aplicada no abdome da gestante na qual são representados, objetivamente, o bebê imaginário e outros elementos da gestação. Objetivou-se, nesta pesquisa, compreender o significado da vivência da Arte da Pintura do Ventre Materno para gestantes. Materiais e Métodos: Estudo exploratório, do tipo antes e depois, qualitativo, desenvolvido em Curitiba, Paraná, Brasil. O grupo estudado incluiu 10 gestantes, com idade gestacional de 24 semanas ou mais. A produção dos dados envolveu: Arte da Pintura do Ventre Materno, fotografia, diário de campo e entrevistas, analisadas com base na análise temática de conteúdo, proposta por Laurence Bardin. Resultados: Emergiram duas categorias: 1) A Arte da Pintura do Ventre Materno promove experiências do núcleo subjetivo da vinculação ou de amor; 2) Comportamentos maternos positivos gerados pela Arte da Pintura do Ventre Materno. Discussão: A interpretação dos dados, fundamentada na teoria de John Condon, possibilitou elaborar um modelo hierárquico da experiência subjetiva da vinculação ou de amor da gestante com o bebê, mediada pela Arte da Pintura do Ventre Materno. Esta técnica artística, associada a uma abordagem humanista, revela-se como uma boa opção de cuidado a ser implementada na atenção à saúde materna. Conclusões: O significado atribuído pelas gestantes à vivência da Arte da Pintura do Ventre Materno indica que a técnica promoveu a experiência do núcleo subjetivo da vinculação ou de amor com o bebê, elucidando o seu potencial na promoção da vinculação pré-natal.

Palavras chave: Arte; Pintura; Comportamento; Amor; Enfermagem.

Abstract

Introduction: The Art of Maternal Womb Painting is a technique applied to the abdomen of the pregnant woman in which the imaginary baby and other elements related to the pregnancy are represented objectively. This research aimed to understand the meaning of the experience of the Art of Maternal Womb Painting for pregnant women. Materials and Methods: Exploratory study, before and after, qualitative, developed in Curitiba, Paraná, Brazil. The group studied included 10 pregnant women, with gestational age of 24 weeks or more. The collected data involved: Art of Maternal Womb Painting, photography, field diary and interviews, analyzed based on the thematic content analysis, by Laurence Bardin. Results: Two categories emerged: 1) The Art of Maternal Womb Painting promotes experiences of the subjective core of attachment or love; 2) Positive maternal behaviors generated by the Art of Maternal Womb Painting. Discussion: The interpretation of the data, based on the theory of Condon, made it possible to elaborate a hierarchical model of the subjective experience of the attachment or love of the pregnant woman with the baby, mediated by the Art of Maternal Womb Painting. This artistic technique, associated with a humanist approach, is a good care option to be implemented in maternal health care. Conclusions: The meaning recognized by pregnant women who experienced of the Art of Maternal Womb Painting indicates that the technique promoted the subjective core experience of attachment or love with the baby, elucidating its potential in promoting antenatal attachment.

Key words: Art; Paint; Behavior; Love; Nursing.

Resumen

Introducción: El Arte de la Pintura del Vientre Materno es una técnica aplicada en el abdomen de la gestante en la cual son representados objetivamente el bebé imaginario y otros elementos de la gestación. El objetivo de esta investigación fue comprender el significado de la vivencia del Arte de la Pintura del Vientre Materno para gestantes. Materiales y Métodos: Estudio exploratorio, del tipo antes y después, cualitativo, desarrollado en Curitiba, Paraná, Brasil. El grupo estudiado incluyó 10 gestantes, con edad gestacional de 24 semanas o más. La producción de los datos involucró: Arte de la Pintura del Vientre Materno, fotografía, diario de campo y entrevistas, analizadas con base en el análisis temático de contenido, propuesta por Laurence Bardin. Resultados: Emergieron dos categorías: 1) El arte de la Pintura del Vientre Materno promueve experiencias del núcleo subjetivo de la vinculación o de amor; 2) Comportamientos maternos positivos generados por el Arte de la Pintura del Vientre Materno. Discusión: La interpretación de los datos fundamentada en la teoría de John Condon, posibilitó elaborar un modelo jerárquico de la experiencia subjetiva de la vinculación o de amor de la gestante con el bebé, mediada por el Arte de la Pintura del Vientre Materno. Esta técnica artística asociada a un enfoque humanista, se revela como una buena opción de cuidado a ser implementada en la atención a la salud materna. Conclusiones: El significado atribuido por las gestantes a la vivencia del Arte de la Pintura del Vientre Materno indica que la técnica promovió la experiencia del núcleo subjetivo de la vinculación o de amor con el bebé, explicando su potencial en la promoción del vínculo prenatal.

Palabras clave: Arte; Pintura; Conducta; Amor; Enfermería.

Como citar este artigo: Mata JAL, Shimo AKK. Arte da pintura do ventre materno e vinculação pré-natal. Rev Cuid. 2018; 9(2): 2145-64. http://dx.doi.org/10.15649/cuidarte.v9i2.499

(c) (i) (5) 2018 Universidad de Santander. Este es un artículo de acceso abierto, distribuido bajo los términos de la licencia Creative Commons Attribution (CC BY-NC 4.0), que permite el uso ilimitado, distribución y reproducción en cualquier medio, siempre que el autor original y la fuente sean debidamente citados. 


\section{INTRODUÇÃO}

A Arte da Pintura do Ventre Materno é uma técnica feita no abdome da gestante na qual são representados, objetivamente, o bebê imaginário e outros elementos ligados à gestação como o cordão umbilical, a placenta, o útero e a bolsa das águas ${ }^{1-2}$.

Trata-se de uma prática que pode ser adotada no pré-natal a partir de 24 semanas gestacionais, quando é possível aplicar a manobra de Leopold Zweifel e constatar a situação, posição e apresentação fetal, permitindo que o bebê seja representado na arte da forma como se encontra no ambiente uterino ${ }^{1}$.

O bebê imaginário é a imagem mental do feto construída pela mãe (ou pelo casal) durante a gravidez ${ }^{3}$. Neste período, os pais adquirem uma representação interna, crescente e elaborada da criança, que abrange uma mescla de fantasia e de realidade, sendo o bebê um recipiente da projeção. É em relação a esta imagem interna que o vínculo emocional se desenvolve ${ }^{4}$.

A vinculação pré-natal (VPN) foi estudada por cientistas que, apoiados por medidas psicométricas, constataram que ela começa durante a gestação ${ }^{5-7}$. Parece fundamentar-se em representações cognitivas do bebê, que envolvem imaginar cenários entre a mãe e a criança, tais como atribuir características psicológicas e físicas ao feto e também uma série de comportamentos que mostram preocupação com ele, como o preparo do ambiente para recebê-lo, a adoção de cuidados com a saúde, a abstenção de substâncias nocivas, entre outros ${ }^{8}$. Trata-se de um sistema representacional de vinculação entre mãe-pai-feto ${ }^{9}$.

Dentre os autores que estudaram profundamente este fenômeno, salienta-se John Condon, que avaliou a qualidade da vinculação, concentrandose especificamente nas atitudes, nos sentimentos e comportamentos para com o bebê $\hat{e}^{2,4}$. Esse teórico elaborou o modelo hierárquico de vinculação no adulto/parental, usado em investigações sobre VPN, focado em experiências afetivas como proximidade, afeto e sentimentos positivos sobre o feto, o desejo de saber sobre ele, assim como representações internas do futuro bebê $\hat{e}^{2,4,10}$.

Condon fundamentou-se no trabalho de Bretherton $^{11}$, para definir a VPN, conceituando-a como um laço emocional que comumente se desenvolve entre mãe-bebê, previamente ao nascimento, representando a forma mais básica de intimidade humana envolvendo um objeto $^{4}$. Na presente pesquisa, adotou-se a teoria deste cientista, que postula cinco experiências subjetivas que expressam a experiência do núcleo subjetivo da vinculação ou de amor ${ }^{4}$, a saber: disposição para conhecer, para estar com/ interagir com, para evitar a separação ou perda, para proteger e para satisfazer as necessidades.

A Arte da Pintura do Ventre Materno oportuniza à gestante expressar sobre o seu bebê imaginário, visualizá-lo e interagir com ele. Por isso, defendese que ela tem potencial para promover a vivência de experiências do núcleo subjetivo da vinculação ou de amor, significativas na constituição da VPN. Objetivou-se, nesta pesquisa, compreender 
o significado da vivência da Arte da Pintura do Ventre Materno para gestantes.

\section{MATERIAIS E MÉTODOS}

Foi desenvolvido um estudo exploratório, do tipo antes e depois, em uma abordagem qualitativa, o qual respeitou os critérios consolidados para investigações desta natureza. Este resultou da tese de doutorado "Vivência da Arte da Pintura do Ventre Materno por Profissionais e Gestantes: Histórias, Emoções e Significados"1, elaborada no âmbito da Faculdade de Enfermagem da Universidade Estadual de Campinas (FEnf/ Unicamp).

O cenário do estudo foi uma unidade de Estratégia de Saúde da Família de Curitiba, Paraná, Brasil. A coleta dos dados ocorreu entre outubro de 2015 e janeiro de 2016, por meio das seguintes estratégias: aplicação da Arte da Pintura do Ventre Materno, entrevista, fotografia e diário de campo.

Definiu-se de forma intencional ${ }^{12}$ o grupo a ser pesquisado e o seu tamanho foi delimitado por meio da saturação de dados ${ }^{13}$. Foram incluídas dez gestantes, considerando os seguintes critérios de elegibilidade: estar vinculada à unidade de saúde estudada e ter 24 semanas de gestação ou mais. $\mathrm{O}$ último item justificou-se pela necessidade de realizar a manobra de Leopold, para desenvolver a Arte da Pintura do Ventre Materno de forma objetiva.
Foi critério de exclusão referir alergia, previamente à coleta, a qualquer componente usado na aplicação da arte. Considerou-se como critérios de descontinuação: deixar de participar de qualquer etapa da investigação; manifestar reação alérgica durante a pintura; e nascer o bebê antes da realização da Arte da Pintura do Ventre Materno. As voluntárias assinaram o Termo de Consentimento Livre e Esclarecido (TCLE) e o Termo de Autorização de Uso da Imagem. Para àquela menor de 18 anos, aplicou-se um Termo de Assentimento, com ciência e aprovação do seu responsável legal.

Todas receberam a mesma intervenção, em grupo único, tendo sua condição verificada antes e após a vivência da Arte da Pintura do Ventre Materno. Esta foi previamente agendada, atendendo à disponibilidade das participantes, assim como o local de sua preferência, podendo ocorrer na unidade de saúde ou no domicílio.

Solicitou-se a cada gestante que relatasse sobre como imaginava o seu bebê, foram feitos os três primeiros tempos da manobra de Leopold Zweifel (situação, posição e apresentação) e auscultados os batimentos cardiofetais. Depois, a primeira autora representou na arte o bebê imaginado descrito pela mãe, a placenta, o cordão umbilical, o útero, a bolsa das águas e outros elementos requeridos (Figura 1). Esta etapa durou em média 60 minutos, sendo registrada por um fotógrafo treinado para a pesquisa ${ }^{1}$. 


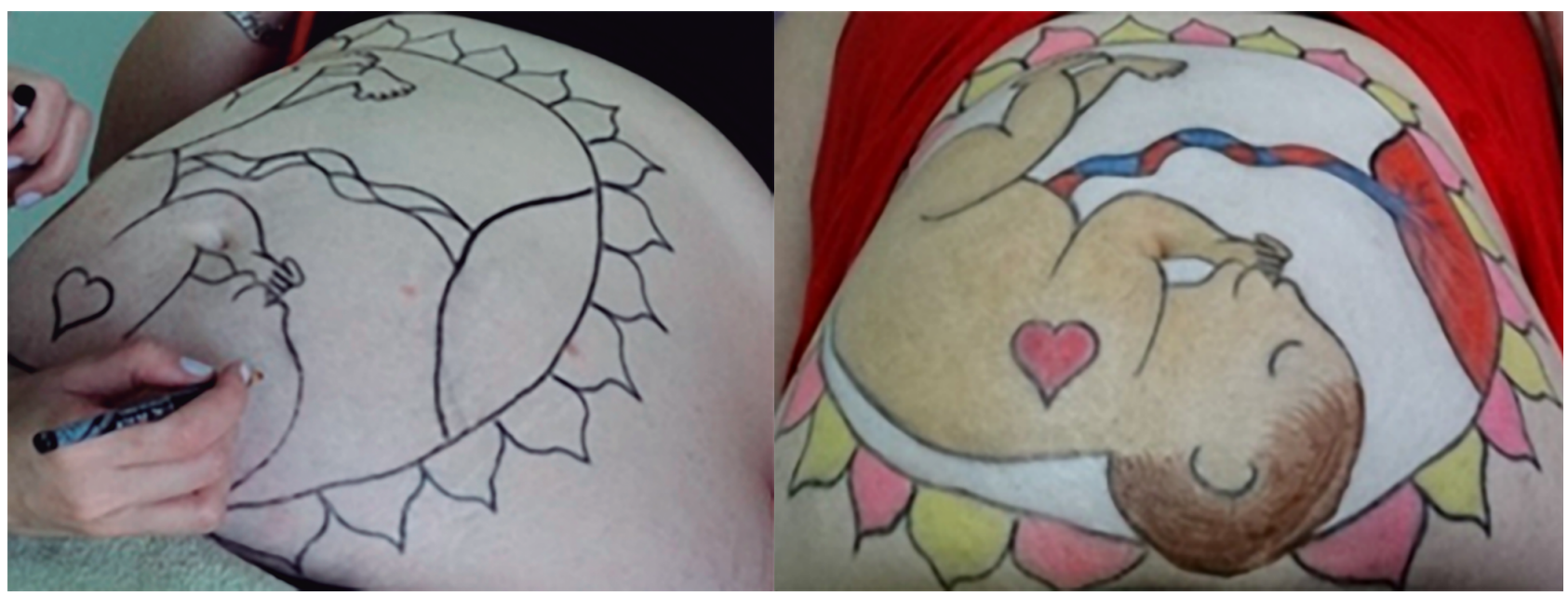

Figura 1 - Sequência de fotos do desenvolvimento da Arte da Pintura do Ventre Materno. Curitiba, PR, Brasil, 2017

Fonte: Tese de doutorado da primeira autora.

As falas foram colhidas em dois momentos: primeiro, na ocasião da pintura, em que foram coletadas informações para a caracterização das participantes e sobre o bebê imaginário e, segundo, até três dias após a ação, com a aplicação de um roteiro guia, incluindo as seguintes perguntas ${ }^{1}$ : 1- Conte-me como você se sentiu durante a realização da pintura do seu ventre; 2- No final, quando lhe mostrei a pintura, o que você sentiu? 3- Após a realização da pintura e saída da unidade de saúde (ou a saída da pesquisadora do seu domicílio) o que você fez? 4- Quando você lavou/ tirou a pintura? Como foi? 5- Tem mais alguma coisa que você gostaria de falar em relação à sua vivência da pintura e/ou sobre o processo póspintura? As entrevistas foram audiogravadas e duraram em média cinco minutos e meio. Todas foram transcritas concomitantemente à coleta.

A análise dos dados fundamentou-se na análise temática de conteúdo, proposta por Laurence Bardin, transcorrendo em três etapas: a) préanálise, com a sistematização das ideias iniciais; b) exploração do material, em que os dados foram transformados em conteúdos temáticos, por meio da codificação dos discursos, delimitando os temas a serem discutidos; c) análise dos conteúdos, envolvendo inferências e interpretações dos achados com base na fundamentação teórica da investigação ${ }^{14}$. Com o intuito de preservar o anonimato, as gestantes foram codificadas com nomes de flores.

Este estudo foi aprovado pelo Comitê de Ética em Pesquisa (CEP) da Unicamp sob o registro CAAE 48174715.1.0000.5404 e pelo CEP da Secretaria Municipal de Saúde de Curitiba.

\section{RESULTADOS}

\section{Caracterização das gestantes}

Quatro participantes tinham idade entre 20 e 29 anos, cinco entre 30 e 39 anos e, uma, menos de 18 anos. Seis se declararam solteiras, três casadas e uma em união estável. Quanto ao número 
de gestações, cinco eram primigestas, três secundigestas, uma tercigesta e uma multigesta. Uma delas já havia vivenciado aborto e outra teve um neomorto, que é a morte ocorrida dentro do período neonatal.

Somente duas referiram ter planejado a gestação. Cinco se encontravam entre 24 e 29 semanas gestacionais e, cinco, entre 30 e 35 semanas. Sete gestantes foram estratificadas como risco habitual e três como alto risco. No que se refere ao sexo do bebê, todas sabiam, sendo cinco do sexo feminino e, cinco, masculino.

\section{Categorias de Análise}

$\mathrm{Na}$ análise das entrevistas, foram identificadas as unidades de significado e elencadas as subcategorias da pesquisa, que resultaram nas seguintes categorias de análise: 1) A Arte da Pintura do Ventre Materno promove experiências do núcleo subjetivo da vinculação ou de amor;

2) Comportamentos maternos positivos gerados pela Arte da Pintura do Ventre Materno.
Salienta-se que, devido à riqueza dos dados, algumas falas deste manuscrito também foram analisadas e apresentadas em outro artigo ${ }^{2}$, o qual focou a identificação da Representação Social diante da vivência da técnica para as gestantes.

\section{A Arte da Pintura do Ventre Materno promove experiências do núcleo subjetivo da vinculação ou de amor}

A Arte da Pintura do Ventre Materno promoveu nas gestantes a vivência de quatro experiências do núcleo subjetivo da vinculação ou de amor, a saber: disposição para conhecer sobre o bebê, para estar com e interagir com ele, para evitar a separação ou perda e para proteger o bebê. Estas constituíram as subcategorias da primeira categoria de análise.

\section{Disposição para conhecer sobre o bebê}

Foi identificado que, ao experimentarem a 'disposição para conhecer', as gestantes elaboraram o bebê imaginário, descrevendo suas características e buscando informações sobre o feto.

Quando você estava pintando assim, eu fiquei imaginando como realmente ele estaria lá dentro. E fiquei pensando: será que ele realmente vai ser assim ou não? Depois que você terminou a pintura, eu fiquei imaginando que ele vai vir acho que igualzinho o que eu imaginei. Espero que venha, né? Achei uma sensação bem gostosa assim, né? De você poder imaginar como ele tá ali dentro, se tá realmente naquela posição. [...] Bem diferente do que a gente imagina, do que a gente vê no ultrassom também, né? Que o ultrassom não tem aquele detalhe assim (Prímula).

Realmente foi assim um momento muito especial pra mim. De eu poder tá vendo ela e como ela tá encaixadinha ali, né? O jeitinho dela. E é realmente bem daquele jeito que eu imagino ela (Jasmim). 
Eu me senti muito feliz. Daí eu queria saber, porque a gente fica curioso pra saber como eles [os bebês] ficam na barriga, né? O jeitinho que eles ficam. Daí deu pra eu ver direitinho a posição que ela tá. O jeitinho que ela tá. Acho que não tem nada que afeta ficar de ponta cabeça, né? Pra eles é normal ficar assim? É a mesma coisa como se estivesse assim normal, né? É que o meu marido estava perguntando: nossa, será que não é ruim ficar de ponta cabeça? Ai meu Deus! A gente fica curioso pra saber. Daí dá mais vontade ainda do que a gente já tava. De que ela nasça logo pra pegar ela. Senti curiosidade. Bastante ansiedade, vontade de ver onde tava o pezinho. E eu gostei. Nossa, amei! Do jeito que eu tava imaginando (Margarida).

Ter representado o bebê imaginário objetivamente, por meio da Arte da Pintura do Ventre Materno, estimulou a consciência das mães em relação às posições fetais.

Parece que eu olhava assim a barriga e olhava ele [o bebê] ali dentro. Ficava imaginando assim: ah, o pezinho dele tá pra cá e, então, ele mexia assim e daí o pezinho dele mexia por cima. E então eu ficava imaginando assim, né? Uma sensação assim gostosa. Assim tipo lá dentro assim (Prímula).

[...] Que emocionante! Que bom! Como eu sou uma privilegiada! E foi uma sensação única, porque é tão abstrato, né? É algo tão, tipo, porque você não consegue tocar, né? Porque ele tá aqui dentro. Quando você vê aquilo exteriorizado de alguma forma, é tão bonito. É tão mágico que até eu coloquei no face [Facebook®]. Que é uma coisa tão divertida, tão bonita. Você fica meio extasiada assim. Você fica pensando: nossa, que legal tá pintando o neném. E ele tá nessa posição mesmo (Lavanda).

A maioria das participantes (nove) mostrou que, ao visualizar a arte pronta, acessou o bebê que idealizou e fantasiou.

Imaginar me deu mais vontade de pegar ainda ela [o bebê] no colo porque imagina, nossa, ela tá enorme! E dai dá impressão que parecia que eu tava vendo ela. Aquele desenho ficou muito igual a ela. Meu Deus, como ficou! E ela é muito fofa (Lírio do Vale).

Eu ficava pensando mais na criança, como é que ela estava mesmo. Estava igual você tava pintando. Foi assim que eu me senti. Eu imaginava que ela estaria assim nessa posição mesmo. Que às vezes a barriga fica meio pontuda de um lado e tal. Daí eu sinto aqui assim. Aí imaginava que ela era assim (Rosa). 
[...] Realmente foi assim um momento muito especial pra mim. De eu poder tá vendo ela e como ela tá encaixadinha ali, né? O jeitinho dela. Eé realmente bem daquele jeito que eu imagino ela (Jasmim).

Uma das entrevistadas referiu não imaginar o bebê. Tal comportamento pode ter relação com as suas experiências gestacionais prévias. Em muitos momentos, ela falou sobre suas gestações de risco, a perda um filho após o nascimento por sepse neonatal e como isso repercutiu no seu relacionamento com o bebê atual, assumindo uma atitude de distanciamento do feto, com indícios de um padrão de vinculação negativo.

[...] eu não faço a menor ideia de como o bebê vai ser. Eu não imagino. [...] Que essa coisa sentimental de... ah, tá esperando um bebê e não sei o quê. Eu sou bem mais realista, sabe? Mas assim, tipo, eu acho que eu fiquei mais emocionada com a reação dos meninos [os dois filhos dela]. [...] Então, assim, eu acho que eu fiquei mais tocada com isso, pela reação deles, dos dois assim, porque eu não sei se é porque eu tive a perda do Júlio [nome fictício atribuído ao filho que faleceu após o nascimento] ou porque todas as minhas gravidezes foram complicadas. Mas assim, eu não sou o tipo que fica muito ansiosa durante a gestação. Acho que quem acaba curtindo mais é a minha mãe e o meu marido, do que eu mesma. Então, o negócio da pintura foi legal por ver a carinha deles [seus filhos] (Gerânio).

Imaginar o bebê é um dos principais comportamentos causados pela experiência da 'disposição para conhecer'. Optou-se por apresentá-la na primeira categoria, devido à sua frequência de aparição nos discursos que a integraram.

\section{Disposição para estar com e interagir com o bebê}

A 'disposição para estar com e interagir com' foi experimentada pelas gestantes durante e após a aplicação da Arte da Pintura do Ventre Materno, sendo significada por elas como uma oportunidade de aproximação com seus filhos.

Eu queria ver, porque minha gravidez não foi planejada e foi difícil no começo a aceitação. Para eu aceitar demorou muito, sabe? Então eu achei que isso pudesse, talvez, me aproximar mais da minha filha. Efoi o que aconteceu. Mas durante a pintura eu fiquei tranquila. Ah, eu estava feliz assim, por estar fazendo uma coisa com ela (Verbena). 
No desenvolvimento da arte, foi identificado que os bebês se movimentavam bastante e, curiosamente, pareciam acompanhar com os seus movimentos toda a execução da pintura. Para algumas das participantes, isso denotou uma interação com o feto.

A bebê mexia bastante. O tempo inteiro tava ali envolvida com a gente também. E depois que eu vi o resultado, não teve como me conter (Jasmim).

As voluntárias consideraram que a Arte da Pintura do Ventre Materno provocou a interação entre mãe-família-feto.

Meu marido achou assim uma coisa maravilhosa. Achou que é muito positivo para a gestante e que só traz benefício mesmo. E eu senti uma aproximação da família também, eles curtiram. Meu pai, minha mãe, meu irmão, eles acharam o máximo assim (Flor de Lótus).

Todo mundo ficou muito feliz. Daí minha irmã já tirou um monte de foto e mandou para o grupo da família. Nossa, daí a galera ficou super feliz de eu tá animada com a gravidez agora, sabe? Porque, tipo, eles viram que eu tava feliz e tal. Foi bem bacana. Foi muito legal (Verbena).

Eu passei a tarde com a minha filha na escolinha. E o tempo inteiro, dava uma meia hora a minha filha vinha de novo pedindo pra ver a barriga. Tanto é que de noite, quando eu fui tomar banho, ela não quis nem deixar que eu passasse o sabão na barriga. Tinha que deixar. Mas ai na hora do banho eu tava passando o sabão e ainda não esfreguei a barriga. Deixei ficar o desenho mesmo. Ai no dia seguinte ela [a filha] queria que eu pintasse a barriga dela e fizesse a bebê na barriga dela também. Um sarro! Daí eu peguei e dei o lápis pra ela e fiz o desenhinho na barriga, de coraçãozinho, na dela também. Daí ela veio e falou: mãe, eu posso pintar a bebê também? Aí veio e passava o lápis, certinho em cima do traço que ficou na minha barriga, da pintura (Jasmim).

\section{Disposição para evitar a separação ou perda}

Ao serem perguntadas sobre quando tiraram a Arte da Pintura do Ventre Materno e como foi o processo, as gestantes demonstraram, por meio das falas, ter experimentado a 'disposição para evitar a separação ou perda'. 
Eu fiquei triste. Foi um processo de desapego. Fiquei triste porque parecia que eu tava apagando ele [o bebê]. Eu fiquei estranha de ontem pra hoje porque parecia uma conexão muito maior do que a gente já tem. E dai hoje, quando eu tive que tirar falei: ai, vou tirar, sabe? E depois que eu saí do banho, eu passei demaquilante e tudo. E eu ainda fiquei horas olhando para a minha barriga sem nada. Parecia que tava faltando alguma coisa. Parece que eu tava muito mais próxima dele por causa do desenho (Flor de Lótus).

Ai, nem fale. Eu não queria tirar porque tava tão gostoso aquilo ali. Nossa, era ela [o bebê] (Lírio do Vale).

A pintura foi tão significativa para as participantes, que o processo de retirada do desenho foi vivenciado de forma dolorosa por elas. Algumas referiram o quão importante foi saber como o bebê estava intraútero e que desejavam permanecer mais tempo com a arte em seu corpo. Por isso, procuraram evitar perder o bebê representado na arte.

[...] Dá vontade de ficar com a pintura. Eu fiquei com dó de tirar assim. Dá vontade de deixar lá. Bom se fosse aquelas de Henna, né? Que não precisava tirar. Só depois de uns dias, né? Mas daí não teve outro jeito. Fui tirando aos pouquinhos assim (Margarida).

[...] É uma coisa muito louca. Acho que a gente é meio doida. Eu fui apagando com cuidado assim, os traços mais fortes assim. E, depois, eu apaguei por inteiro assim. E dá uma sensação de vazio. Tipo, ah que pena! Agora só daqui três meses, né? Quando ele nascer mesmo. Que eu vou poder ver efetivamente o rosto dele e tal. Uma sensação de perda assim. É uma coisa esquisita (Lavanda).

Olha, eu nem queria tirar na verdade. Mas dai já com a água assim, né? Eu fui esfregando e, ai, que dozinha de tirar ele no banho. Meu Deus! Daí tive que tirar. Ah, sei lá. Foi estranho. Parecia que eu tava tirando ele de dentro de mim. Ai, foi muito estranho! Porque tava real, sabe? Daí eu não enxergava a pintura, eu enxergava ele em mim. Daí foi a mesma coisa que tivesse tirando ele de mim. Foi estranho (Tulipa).

\section{Disposição para proteger o bebê}

As gestantes apresentaram a 'disposição para proteger' o bebê representado na arte, considerado por elas a imagem fidedigna do filho. A Arte da Pintura do Ventre Materno consolidou a representação do feto, elaborada por cada mãe, dando objetividade à criança fantasiada. O que antes integrava apenas o imaginário das entrevistadas tornou-se algo mais próximo da realidade delas, que passaram a tratar a pintura como o seu próprio bebê. 
Eu ia tirar ontem e eu não consegui. Eu dormi com a pintura [risos]. Tirei só hoje. Fiquei agoniada, parece criança quando vai em festinha de aniversário e fica assim, que não se mexe. Eu não queria que o cinto de segurança apagasse, eu não queria que a roupa encostasse para não apagar. E daí o meu marido, quando eu falei com ele à noite, por causa da diferença de horário [mora fora do país e viu a pintura por vídeo], ele falou: mas você não vai tomar banho? Dai eu falei assim: olha, tomei banho antes de ir e eu vou dormir assim. Porque na verdade, no meu modo de ver, é até um respeito ao bebê, porque foi uma ligação com ele tão grande que eu falei: deixa mais um pouquinho ele aqui na minha barriga. E hoje de manhã foi tão incrível que o tipo de blusa que eu coloquei ele deixou a marca certinha. Não tinha muitas cores ainda, mas tinha todo o desenho. Eu fiquei horas olhando no espelho ainda (Flor de Lótus).

Ah, primeiro foi aquele cuidado, né? Porque a gente terminou a pintura ali e eu já tinha consulta. Dai fui pra consulta. A reação do médico foi incrível, porque ele achou muito bacana, sabe? Nossa, que lindo [disse o médico]. Ele gostou bastante. E dai fiquei com cuidado o tempo todo. Ficava puxando a roupa pra que ela não encostasse, porque eu não queria que borrasse (Jasmim).

\section{Comportamentos maternos positivos gerados pela Arte da Pintura do Ventre Materno}

Os principais comportamentos e sentimentos desencadeados pela vivência da Arte da Pintura do Ventre Materno estão dispostos nesta categoria, emergida a partir das subcategorias: busca por informações, por proximidade e proteção do bebê; prazer, relaxamento e valorização pessoal da gestante.

\section{Busca por informações, por proximidade e proteção do bebê}

A fala a seguir demonstra a presença do comportamento de busca por informações.

Foi gostoso. Ah, era uma coisa mágica, né? Porque desenhar do jeitinho que ele [o bebê] tá ali. Ah, foi muito bom! Muito bom. Vontade de ver ele logo. Quanto mais traço você desenhava nele, mais eu tinha vontade de ver ele. Como ele é (Tulipa). 
A busca por proximidade também foi expressada.

Na verdade, é muito emocionante. Porque é uma coisa que eu não esperava. Eu já tinha visto, mas não tinha visto de perto. Sabia que se fazia esse tipo de arte, mas não imaginava em mim mesma. E achei aquilo muito real. [...] Parecia que o bebê estava ali, estava muito mais próximo de mim. E é uma realidade, uma aproximação muito grande (Flor de Lótus).

Eu queria que todo mundo pudesse fazer. Porque é tão legal e isso te aproxima tanto do teu neném, que cria um vínculo tão grande com ele, né? Tá vendo que ele tá ali. E ele é o neném! Ele tá ali! Ele vai vir daqui a pouco e, tipo, ele deu um olá (Lavanda).

Este comportamento também ocorreu na interação das gestantes com a primeira autora. Durante a realização da arte, estabeleceu-se uma relação terapêutica com as voluntárias, fundamentada em uma abordagem humanista, com acolhimento empático e escuta sensível.

Após concluída a última etapa da coleta, as participantes foram presenteadas com algumas fotos. Elas retribuíram com expressões de carinho e pediram para manter contato. Um fato inusitado é que, na medida em que os bebês iam nascendo, as mulheres contatavam a autora e enviavam fotos dos filhos, comparando-os à Arte da Pintura do Ventre Materno e relatando as suas experiências. Verificou-se que a vivência da arte também gerou a aproximação entre as entrevistadas e a enfermeira obstetra que a aplicou.

O comportamento de proteção do bebê representado apareceu nos discursos de todas as participantes. Uma delas permaneceu três dias com a pintura, mantendo todo o cuidado para que não apagasse, maximizando o tempo no modo de vinculação.

Eu cheguei em casa na sexta-feira mesmo e tomei um banho. Mas não esfreguei a barriga. Então até agora [3 dias depois] eu ainda tenho um pouquinho de manchinha aqui. Porque eu tô evitando esfregar. Passo sabonete de leve, mas não tô esfregando para sair. No umbigo eu ainda tenho a mãozinha dela. Ai, foi como se eu tivesse tirando ela ali na hora, sabe? Porque eu não queria que ela saísse da minha barriga, o desenho dela. Porque, assim, é tão engraçado, porque conforme eu via ela se mexendo, eu sabia que ali tava o pezinho dela mexendo. Eu sei ainda onde ela tá, conforme o movimento dela. Mas é como se eu já tivesse perdida. Como se eu me perdesse dela e não soubesse onde ela tá bem certinho, sabe? As costinhas, a bundinha, a cabecinha (Jasmim). 


\section{Prazer, relaxamento e valorização pessoal da gestante}

Durante a pintura, as gestantes conversavam bastante, expressando sobre o trabalho, seus filhos, a relação com o companheiro e outros membros da família, as expectativas acerca da gestação atual e do parto, seus medos, anseios, suas dificuldades, dúvidas e alegrias (registros do diário de campo). Algumas caíram em sono profundo durante a ação. Tais fatores, associados à abordagem humanista da enfermeira que coletou os dados, promoveram um momento prazeroso, alegre e de relaxamento para as voluntárias.

Como eu trabalho em ambiente movimentado, Nossa Senhora, aquilo ali foi uma terapia pra mim. Foi maravilhoso. Tem hora que você precisa de um cantinho pra descansar. Eu só não sei como eu não dormi na maca. Porque tava tão bom. Tão gostoso. Eu me admiro com o teu trabalho. Deus abençoe (Lírio do Vale).

Esse momento foi um momento como se tivesse assim relaxando. Como se fosse uma terapia. Aquela coisa assim que foi um momento especial, né? Eu senti isso. Um momento bom. Foi isso que eu senti. Que ainda mais com essa situação que eu tô e tal [companheiro estava com problema de saúde]. Ás vezes é estressante e tal. Ai cheguei assim, meio agitada. E quando eu fiz, eu saí assim bem relaxada. Bem leve. Ajudou bastante (Rosa).

Daí depois eu fiquei com sono assim. Não sei o que deu. Dá sono mesmo, né? Dá muito sono! Mas ah, foi bem gostoso. E nas próximas gravidezes assim, não digo agora, né? Mas eu vou querer fazer em todas que eu tiver (Tulipa).

Todas as participantes relataram ter se sentido felizes ao vivenciarem a Arte da Pintura do Ventre Materno. Algumas falas seguem abaixo:

[...] Como eu sentia? Ah, eu ficava feliz, né? Tipo, ah, eu acho que meu bebê vai ser assim oh! Vocês tão me olhando? Vai ser assim! (Prímula)

Eu fiquei emocionada. Com certeza eu fiquei muito emocionada. Fiquei feliz. Igual eu falei pra você, que eu tava conseguindo me aproximar dela, sabe? Porque é difícil a minha relação com ela. Assim como eu falei para você, demorou para eu aceitar. Entendeu? E eu me sinto culpada por isso. Eu me sinto culpada por muitas coisas que eu não faço pra ela e que eu deveria fazer. Eu me senti bem. Me senti bem emocionada. É igual eu falei para você, sabe? De eu tá me aproximando dela, eu ver o rostinho dela e eu ter materializado ela dentro da minha barriga. E depois eu fiquei feliz. Eu fiquei muito feliz! (Verbena) 
As voluntárias também referiram que se sentiram valorizadas por ter vivenciado a arte visual, e pela atenção recebida das pessoas que a viam nos seus ventres.

Você viu a hora que eu saí, né? Me levaram pra dentro da sala e todo mundo foi lá me ver. Ai, é tudo de bom! Meu Deus! Maravilhoso. E quando eu tava na rua, o pessoal veio me perguntar se era tatuagem. Foi muito legal! Ali embaixo na recepção teve médico que veio pedir para tirar foto. Muito legal. Eu me senti importante naquele dia porque não tinha um que não vinha falar comigo (Lírio do Vale).

O exibicionismo da mãe, que já é a barriga, eu acho que fica mais evidente ainda com a pintura, porque você quer mostrar o teu bebê. E as próprias pessoas que veem fazem uma conexão com o teu bebê (Flor de Lótus).

E eu tava com a barriga exposta, né? E todo mundo olhava. [...] Ah, foi muito legal assim. Eu me senti toda, toda, né? Por mais vergonha que eu tivesse, eu fiquei bem. Ai que chique, eu tenho minha barriga pintada! Foi muito legal. Dai eu vim pra casa e daí tirei mais um monte de foto. Eu e a barriga assim. Eu e a barriga pintada. Tiramos um monte de foto. [...] Ai depois postei no face [Facebook $\left.{ }^{\circledR}\right]$. E dai todo mundo comentou, achou lindo e maravilhoso. Ai eu cheguei no trabalho e tava ainda com a barriga pintada e as meninas: nossa, tá com a barriga pintada! Falei: tô! Daí elas: que bonito, que legal. Como que foi e tal? Falei que foi super legal. E eu fiquei me sentindo (Lavanda).

\section{DISCUSSÃO}

Nessa pesquisa, os fatores idade, escolaridade, estado marital, paridade, planejamento da gestação e risco gestacional parecem não ter influenciado na qualidade da experiência do núcleo subjetivo da vinculação ou de amor com o bebê, pois todas as participantes apresentaram indícios de que estavam em modo de vinculação e, a maior parte (nove), mostrou sentimentos e comportamentos que denotam vinculação positiva.
Somente uma gestante apresentou indícios de vinculação negativa ${ }^{4}$, relacionada à perda perinatal anterior, apresentando ambivalência, preocupação acentuada com o feto e menor entrega às experiências do núcleo subjetivo da vinculação ou de amor. Já foi constatado, em investigações científicas, que a história da gravidez e o número de filhos vivos são preditores para o vínculo entre a mãe e o feto ${ }^{15-16}$.

Estudos evidenciam que a idade gestacional é o preditor mais forte da $\mathrm{VPN}^{17-18}$. À medida que a gestação avança, a vinculação materno-fetal aumenta $^{9,15,16,18-21}$. As participantes deste trabalho 
encontravam-se entre o segundo e o terceiro trimestre gestacional, momentos nos quais, em conformidade com as pesquisas supracitadas, a vinculação costuma ser maior. Fator que favoreceu, nesta investigação, a identificação de indicadores da presença da experiência do núcleo subjetivo da vinculação ou de amor com o bebê.
O modelo hierárquico de vinculação no adulto/ parental (Figura 2), proposto por Condon, foi concebido a partir de trabalhos sobre a natureza do vínculo no adulto e da experiência atinente ao luto, revelando que o núcleo da vinculação é a experiência do amor ${ }^{4}$.

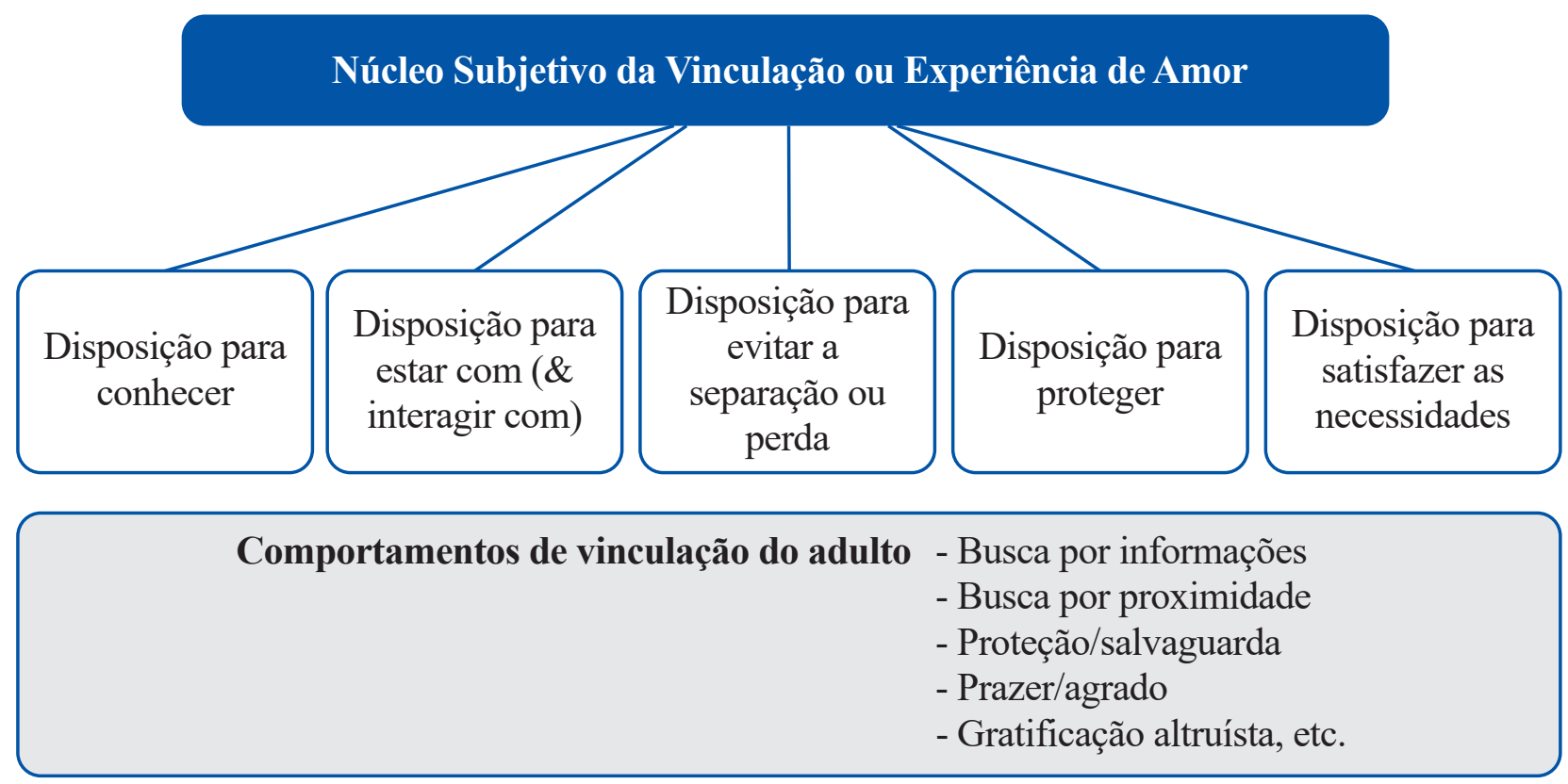

Figura 2. Modelo hierárquico de vinculação parental, de John Condon ${ }^{4}$, traduzido livremente ${ }^{1-2}$. Curitiba, PR, Brasil. 2017

Fonte: Tese de doutorado da primeira autora.

Esse autor apresenta cinco experiências subjetivas (segundo nível do modelo), denominadas 'disposições ou necessidades', que expressam a experiência da vinculação ou de amor e que podem gerar comportamentos evidentes (terceiro nível do modelo). Ele não propõe que estas experiências definam a vinculação ou sejam equiparadas ao amor parental. Dentro da sua teoria, estas disposições são tratadas como indicadores ou presença provável da vinculação ${ }^{4}$.
Adisposição para conhecer significa a curiosidade sobre a natureza do objeto amado ${ }^{4}$. Ao vivenciála, a mulher cria características do feto e busca informações sobre ele, podendo elaborar o bebê imaginário. $\mathrm{O}$ que foi claramente identificado nas participantes desta pesquisa.

Durante a gestação, além do corpo feminino se encarregar pelo crescimento físico do feto, ocorre, psiquicamente, a construção de uma imagem mental do bebê ${ }^{3}$. Entre a mãe e o feto 
é estabelecida uma relação próxima, distinta de qualquer outra, pois os protagonistas são invisíveis um ao outro e, mesmo que a mulher sinta o bebê a partir de determinado período gestacional, não tem certezas objetivas de suas formas e características físicas. Este vazio é insuportável, e os pais o preenchem elaborando determinada personagem, o bebê imaginário ${ }^{9,22}$, essencialmente pré-consciente, marcado por idealizações e fantasias ${ }^{23-24}$.

A Arte da Pintura do Ventre Materno pode contribuir para o alívio deste sentimento de vazio, pois nela o bebê imaginado é representado objetivamente para a mãe (posicionamento intraútero, tamanho aproximado e características descritas), fomentando a fantasia e a visualização.

O bebê imaginário alicerça as expectativas maternas em relação ao bebê real, sendo elas mais frequentes no segundo trimestre gestacional, fase em que o feto revela a sua existência por meio da movimentação fetal ${ }^{25}$. O investimento feito pela mãe na constituição psíquica do bebê favorece o exercício da maternidade e a prepara para o encontro com ele ${ }^{26}$.

Há mulheres que não investem no feto e nem esperam algo dele, por medo de que a realidade não satisfaça os seus desejos ${ }^{27}$. O que se relaciona ao caso de Gerânio, que demonstrou manter um distanciamento do bebê, evitando criar expectativas e imaginá-lo.

A mãe necessita personificar o filho para que, no nascimento, não se depare com alguém totalmente estranho a ela ${ }^{26}$. $\mathrm{O}$ ato de descrever o bebê imaginado e caracterizá-lo, estimulado na técnica da Arte da Pintura do Ventre Materno, promove a personificação da criança e a insere no mundo simbólico materno e/ou familiar.

A disposição para estar com e interagir com envolve o desejo de interação com o objeto e a satisfação e o prazer provenientes desta experiência. A gestante costuma interagir com seu bebê por meio de palpação, conversando com ele ${ }^{4}$, e sentindo os seus movimentos. A VPN aumenta com as primeiras percepções dos movimentos fetais $^{20-21}$. Para a maior parte das mulheres, sentir o bebê é uma gratificação pelos desconfortos gerados pelas modificações gestacionais ocorridas no primeiro trimestre, contribuindo para os sentimentos de personificação do feto 9 .

A maior interação entre os familiares, referida pelas mulheres que vivenciaram a arte, se mostra como fator significativo, pois pode influir no processo de vinculação e na manutenção do bem-estar materno. Segundo pesquisa, o apoio familiar no período pré-natal é um elemento que proporciona fortaleza e segurança à gestante, reduzindo riscos associados à falta de suporte durante a gestação ${ }^{28}$.

No terceiro trimestre gestacional, fase na qual a maioria das gestantes se encontravam, o feto organiza sua atividade motora como resposta comportamental a estímulos cinestésicos, auditivos, vestibulares e visuais, posturas e comportamentos motores específicos externos e internos ${ }^{29}$. O desenvolvimento da Arte da Pintura do Ventre Materno envolve vários destes estímulos, o que pode ter repercutido em um comportamento ativo do bebê, representado pelas mães como a interação do filho com elas e uma forma dele mostrar a sua presença. 
Uma pesquisa brasileira constatou que, para as gestantes, a realização do ultrassom (US) contribui para a promoção do vínculo pré-natal, reduz a ansiedade com relação à saúde da criança e colabora na assimilação da gestação. A VPN fortalece-se diante da possibilidade de ver o bebê e também de identificar o seu sexo ${ }^{30}$.

Saber o sexo da criança antes do nascimento, entre outras características, pode ajudar a materializar a relação entre mãe e filho, pois possibilita conhecê-lo, atribuir-lhe identidade, atributos, sentimentos e expectativas ${ }^{25}$.

O US obstétrico impacta positivamente na VPN, potencializando o seu aumento ${ }^{18,20,31}$. Contudo, a sua dimensionalidade não tem influência na vinculação, seja materna ou paterna ${ }^{32}$. Ter visualizado o bebê objetivamente, por meio da Arte da Pintura do Ventre Materno, estimulou nas voluntárias comportamentos similares àqueles gerados pela vivência do US obstétrico, apontados nas pesquisas citadas.

A utilização do US na obstetrícia tem sido crescente, sendo comtemplada em protocolos de assistência pré-natal. As mulheres costumam requerer essa tecnologia na busca por conhecer sobre o estado do bebê intraútero e, por vezes, acabam sendo submetidas ao exame excessivamente.

Um estudo internacional revelou que a frequente exposição do feto humano a ondas de US está associada com uma diminuição no peso corporal do recém-nascido ${ }^{33}$. Reconhece-se a necessidade de desenvolvimento de mais pesquisas científicas sobre este aspecto, mas, até que se tenham evidências robustas sobre esse tema, é importante considerar que o risco oferecido ao bebê, pela exposição indiscriminada ao US convencional, não é zero. Este deve ser reservado para casos com real indicação clínica.

A Arte da Pintura do Ventre Materno pode ser uma prática adotada pelos profissionais na atenção pré-natal, quando a mulher busca conhecer o status fetal intraútero, podendo desencadear comportamentos e sentimentos similares à vivência do US obstétrico, mas sem efeitos nocivos ao feto.

No que se refere à disposição para evitar a separação ou perda, Condon ${ }^{4}$, afirma que ela pode ser vivenciada na realidade ou em fantasia, se manifestando naturalmente por causa do sofrimento experimentado neste tipo de experiência. A força de ligação com o objeto influencia na intensidade desta disposição ${ }^{4}$. Ela pode se expressar em comportamentos de salvaguarda, proteção e de contato prolongado com o objeto amado. Todos eles foram apresentados em diferentes intensidades pelas voluntárias (nove).

No construto de Condon ${ }^{4}$, existem quatro padrões de VPN que estão relacionados à qualidade da vinculação e à intensidade da preocupação dos pais, sendo: 1- qualidade de vinculação forte e segura, em que se apresentam altamente preocupados com o feto e sua intensidade é acompanhada por sentimentos de proximidade, ternura e desejo para com o bebê; 2- qualidade da vinculação positiva e baixa preocupação, 
em que dedicam menos tempo entregandose às experiências de vinculação ou possuem baixa preocupação com o bebê; 3- qualidade de vinculação negativa, na qual gastam pouco tempo no modo de vinculação ou têm pouco interesse ou baixa preocupação com o feto; 4- qualidade de vinculação negativa, em que apresentam muita preocupação com o feto, acompanhada de ambivalência e sem afeto ${ }^{4}$.

A qualidade da vinculação também inclui o tempo gasto no modo de vinculação, representando a preocupação com o feto, o tempo dedicado a sonhar, imaginar, palpar ou falar sobre ele e sentimentos que acompanham estes comportamentos ${ }^{4,9}$.

As voluntárias que apresentaram os comportamentos de imaginar o bebê, busca por informações, por proximidade, proteção, prazer e evitaram a separação ou perda do feto representado na arte, prolongando o contato com a pintura e o tempo no modo de vinculação, mostraram indícios de desenvolvimento de um padrão de vinculação forte e seguro.

A disposição para proteger relaciona-se à proteção do objeto de influências que podem ser prejudiciais à sua existência ou causar- lhe injúrias. Pode, ou não, ser expressa em comportamentos de proteção ${ }^{4}$. No caso das participantes da pesquisa, este comportamento ocorreu de forma unânime.

Os comportamentos que denotam prazer, relaxamento e valorização pessoal, provocados pela Arte da Pintura do Ventre Materno, são importantes para a adaptação da mulher ao processo gestacional e na qualidade da vinculação. O contato com a criança real ou imaginária pode gerar diferentes emoções agradáveis, prazeres, momentos de contentamento e entusiasmo ${ }^{34}$.

A interpretação dos dados dessa pesquisa, fundamentada na teoria de Condon ${ }^{4}$, possibilitou elaborar um modelo hierárquico da experiência subjetiva da vinculação ou de amor da gestante com o bebê, mediada pela Arte da Pintura do Ventre Materno (Figura 3).

Esta técnica artística representa um meio para acessar objetivamente o bebê imaginário, servindo de gatilho (primeiro nível do modelo) para a vivência de experiências do núcleo subjetivo da vinculação ou de amor com o bebê (segundo nível do modelo), desencadeando comportamentos e sentimentos maternos significativos para a VPN (terceiro nível do modelo). 


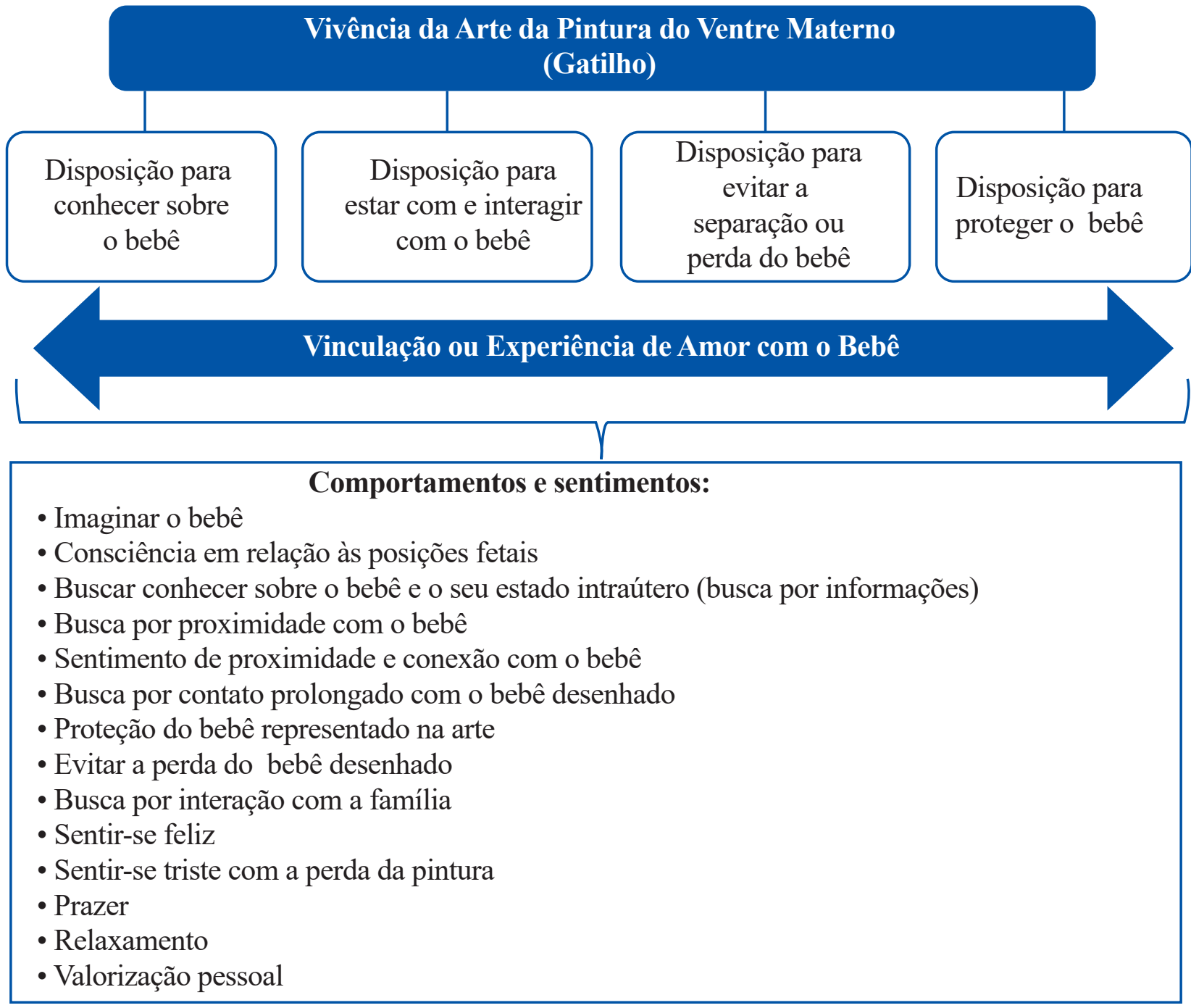

Figura 3. Modelo hierárquico da experiência subjetiva da vinculação ou de amor da gestante com o bebê, mediada pela Arte da Pintura do Ventre Materno ${ }^{1}$, baseado na teoria de Jonh Condon $^{4}$

Diante do exposto, esta arte visual, associada a uma abordagem humanista, revela-se como uma boa opção de cuidado a ser implementada na atenção à saúde materna. A enfermagem, campo que possuí raízes humanistas, desde seus primórdios valorizou o uso das artes na assistência, reconhecendo seus efeitos terapêuticos. Florence Nightingale, sua precursora, recomendava a utilização de plantas de cores fortes, quadros ou gravuras nos ambientes e a aplicação da leitura, da escrita e do bordado como estratégias para reduzir o estresse nos doentes ${ }^{35}$.

Essa investigação ilumina os pressupostos da enfermagem, agregando conhecimentos e valor a ela, por meio do estudo e da integração de uma nova arte visual no cuidado. Salienta-se que as autoras defendem o uso da Arte da Pintura do Ventre Materno como recurso terapêutico no cuidado obstétrico, por isso, houve o risco de 
tendenciamento no estudo, representando uma limitação. Para amenizá-la, a produção dos dados foi desenvolvida de maneira criteriosa, garantindo o rigor científico.

Além disso, os resultados e as inferências foram analisados e discutidos com mais cinco profissionais de saúde e cientistas, externas à coleta, o que colaborou para manejar esta questão.

\section{CONCLUSÕES}

Esse trabalho se fundamentou em pressupostos da psicologia para compreender o significado atribuído por gestantes à vivência da Arte da Pintura do Ventre Materno, transferindo ao campo da enfermagem conhecimentos que contribuíram para a construção teórica sobre esta arte visual.

Os comportamentos, sentimentos e significados, emergidos nas falas das participantes, elucidam que a Arte da Pintura do Ventre Materno promoveu quatro experiências do núcleo subjetivo da vinculação ou de amor com o feto, sendo: a disposição para conhecer, para estar/ interagir com, para evitar a separação ou perda e para proteger o bebê. O que configura esta técnica artística em uma estratégia que pode estimular a experiência da VPN.

Por se tratar de uma investigação inédita, considera-se importante o desenvolvimento de outras pesquisas, que tratem da medição da VPN diante da experiência dessa arte, a fim de dar mais corpo ao conhecimento produzido até aqui e ampliar a sua aplicação no cuidado à saúde materna.
Agradecimentos: Agradecemos a todas as gestantes que participaram dessa pesquisa.

Conflito de interesses: as autoras declaram que não há conflito de interesses.

\section{REFERÊNCIAS}

1. Mata JAL. Vivência da Arte da Pintura do Ventre Materno por Profissionais e Gestantes: Histórias, Emoções e Significados [Tese]. Campinas (SP): Faculdade de Enfermagem, Universidade Estadual de Campinas; 2017.

2. Mata JAL, Shimo AKK. A representação social da Arte da Pintura do Ventre Materno para gestantes. Revista Pesquisa Qualitativa. 2017; 5(8): 250-68.

3. Stern DN, Bruschweiller-Stern N. The birth of a mother. 1nd. Estados Unidos da América: Perseus Books; 1999.

4. Condon JT. The assessment of antenatal emotional attachment: development of a questionnaire instrument. British Journal of Medical Psychology. 1993; 66(2):16783. https://doi.org/10.1111/j.2044-8341.1993.tb01739.x

5. Lumley JM. Attitudes to the fetus among primigravidae. Australian Pediatric Journal. 1982; 18 (2): 106-9. https://doi.org/10.1111/j.1440-1754.1982.tb02000.x

6. Cranley MS. Development of a tool for the measurement of maternal attachment during pregnancy. Nursing Research. 1981; 30(5): 281-4. https://doi.org/10.1097/00006199-198109000-00008

7. Muller ME, Ferketich S. Factor analysis of the maternal fetal attachment scale. Nursing Research. 1993; 42(3): 144-7.

8. Salisbury A, Law K, LaGasse L, Lester B. Maternal-fetal attachment. Journal of American Medical Association. 2003; 289(13):1701. http://dx.doi.org/10.1001/jama.289.13.1701

9. Camarneiro APF. Vinculação pré-natal e organização psicológica do homem e da mulher durante a gravidez: relação com o tipo de parto e com a patologia obstétrica dos II e III trimestres de gestação [Tese]. Lisboa (PT): Faculdade de Psicologia, Universidade de Lisboa; 2011.

10. Priel B, Besser A. Vulnerability to postpartum depressive symptomatology: Dependency, self-criticism and the moderating role of antenatal attachment. Journal of Social \& Clinical Psychology. 1999; 18: 240-53.

http://dx.doi.org/10.1521/jscp.1999.18.2.240

11. Bretherton I. Attachment theory: retrospect and prospect. In: Bretherton I, Waters E. (Eds.). Growing Points of Attachment Theory and Research. Monographs of the Society for Research in Child Development. 1985: 3-35. https://doi.org/10.2307/3333824

12. Polit DF, Beck CT. Fundamentos de Pesquisa em Enfermagem: avaliação de evidências para a prática da enfermagem. 7. ed. Porto Alegre: Artmed; 2011. 
13. Fontanella BJB, Ricas J, Turato ER. Amostragem por saturação em pesquisas qualitativas em saúde: contribuições teóricas. Cad. Saúde Pública. 2008; 24(1): 17-27.

http://dx.doi.org/10.1590/S0102-311X2008000100003

14. Bardin L. Análise de conteúdo. Lisboa: Edições 70; 2009.

15. Lindgren K. Relationships among maternal-fetal attachment, prenatal depression, and health practices in pregnancy. Research in Nursing and Health. 2001; 24(3): 203-17. https://doi.org/10.1002/nur.1023

16. Honjo S, Arai $S$, Kaneko $H$, Ujiie $T$, Murase $S$, Sechiyama H, et al. Antenatal depression and maternalfetal attachment. Psychopathology. 2003; 36(6): 304-11. http://dx.doi.org/10.1159/000075189

17. Brandon AR, Trivedi MH, Hynan LS, Miltenberger PD, Labat DB, Rifkin JB, et al. Prenatal depression in women hospitalized for obstetric risk. Journal of Clinical Psychiatry. 2008; 69(4): 635-43. https://doi.org/10.4088/JCP.v69n0417

18. Yarcheski A, Norreen E, Mahon TJ, Yarcheski MM, Hanks BL, Cannela A. A Meta-analytic study of preditors of maternal-fetal attachment. International Journal of Nursing Studies. 2009; 46(5): 708-15. http://dx.doi.org/10.1016/j.ijnurstu.2008.10.013

19. Cannella BL. Maternal-fetal attachment: an integrative review. Journal of Advanced Nursing. 2005; 50(1): 60-8. https://doi.org/10.1111/j.1365-2648.2004.03349.x

20. Righetti PL, Dell‘Avanzo M, Grigio M, Nicolini U. Maternal/paternal antenatal attachment and forthdimensional ultrasound technique: a preliminar report. British Journal of Psychology. 2005; 96(1):129-37. https://doi.org/10.1348/000712604X15518

21. Vedova AMD, Dabrassi F, Imbasciati A. Assessing prenatal attachment in a sample of Italian women. Journal of Reproductive and Infant Psychology. 2008; 26(2): 8698. https://doi.org/10.1080/02646830701805349

22. Raphael-Leff J. Psychological Processes of Childbearing. 4nd. Great Britain: The Anna Freud Centre; 2009.

23. Colman L, Colman A. Gravidez - a experiência psicológica. Lisboa: Colibri; 1994.

24. Solis-Ponton L. (Org). Ser pai, ser mãe- parentalidade: um desafio para o terceiro milênio. São Paulo: Casa do Psicólogo; 2004.

25. Piccinini CA, Gomes AG, Moreira LE, Lopes RS. Expectativas e sentimentos da gestante em relação ao seu bebê. Psicologia: Teoria e Pesquisa. 2004; 20(3): 223-32. https://doi.org/10.1590/S0102-37722004000300003

26. Brazelton B, Cramer B. As primeiras relações. São Paulo: Martins Fontes; 1992.

27. Raphael-Leff J. Gravidez: a história interior. Reino Unido: Karnac Books LTDA; 2015.

28. Moya-Plata D, Guiza-Salazar IJ, Mora-Merchán MA. Ingreso temprano al control prenatal em uma unidade materno infantil. Rev Cuid. 2010; 1(1): 44-52. http://dx.doi.org/10.15649/cuidarte.v1i1.73

29. Delassus JM. O génio do feto: vida pré-natal e origem do homem. São Paulo: Instituto Piaget; 2002.
30. Piccinini CA, Carvalho FT, Ourique LR, Lopes RS. Percepções e sentimentos de gestantes sobre o pré-natal. Psic. Teoria e Pesquisa. 2012; 28(1): 27-33. https://doi.org/10.1590/S0102-37722012000100004

31. Sedgmen B, McMahon C, Cairns D, Benzie RJ, Woodfield RL. The impact of two-dimensional versus three-dimensional ultrasound exposure on maternal-fetal attachment and maternal health behavior in pregnancy. Ultrasound Obstet Gynecol. 2006; 27(3): 245-51.

https://doi.org/10.1002/uog.2703

32. Rustico MA, Mastromatteo C, Grigio M, Maggioni C, Gregori D, Nicolini U. Two-dimensional vs. twoplus four-dimensional ultrasound in pregnancy and the effect on maternal emotional status: a randomized study. Ultrasound Obstetric and Gynecolgy. 2005; 25(5): 46872. https://doi.org/10.1002/uog.1894

33. Newnham JP, Evans SF, Michael CA, Stanley FJ, Landau LI. Effects of frequente ultrasound during pregnancy: a randomised controlled trial. Lancet. 1993; 342: 887-91.

https://doi.org/10.1016/0140-6736(93)91944-H

34. Ekman P. A linguagem das emoções. São Paulo: Lua de Papel; 2011.

35. George JB. Teorias de enfermagem: os fundamentos à prática profissional. 4. ed. Porto Alegre: Artes Médicas Sul; 2000. 